\title{
PHENOLIC ACIDS OF WORMWOODS OF THE ORDER Frigidae
}

\author{
E. N. Sal'nikova, N. F. Komissarenko, A. I. Derkach, \\ S. E. Dmitruk, and G. I. Kalinkina
}

UDC 547.962

Continuing an investigation of the phenolic compounds of the epigeal part of Artemisia jacutica Drob, A. sieversiana Wild., and $A$. absinthium L. [1], we have isolated the phenolic carboxylic acids from a $70 \%$ ethanolic extract. An ethyl acetate fraction obtained by a method described previously [1] was, after the elimination of the extractant, deposited on a column of polyamide sorbent or of a powder of microcrystalline cellulose. The phenolic acids were eluted from the polyamide with water and with aqueous alcohol havng increasing concentrations of ethanol. The total fractions were rechromatographed on FN-11 paper, and the individual substances were eluted with hot 50\% ethanol. After recrystallization, substances (I), (II), (III) and (VII) were obtained. The cellulose-containing column was eluted with $2 \% \mathrm{CH}_{3} \mathrm{COOH}$. The eluted substances (IV), (V), and (VI) were recrystallized from methanol. Substances (I-VII) were identified on the basis of qualitative reactions, chromatographic behavior, physical constants, the products of alkaline hydrolysis, IR and UV spectra with diagnostic additives, and comparison with authentic specimens. Authenticity was confirmed by HPLC $[2,3]$.

Substance (I) was vanillic acid $\mathrm{C}_{8} \mathrm{H}_{8} \mathrm{O}_{4}, \mathrm{mp} 202-204^{\circ} \mathrm{C}$, UV spectrum $\lambda_{\max }{ }^{\mathrm{E}}{ }^{\mathrm{H}} \mathrm{HH} 290,260 \mathrm{~nm}$.

Substance (II) was p-hydroxybenzoic acid, $\mathrm{C}_{7} \mathrm{H}_{6} \mathrm{O}_{3}, \mathrm{mp} 210-211^{\circ} \mathrm{C}$. UV spectrum: $\lambda_{\max }{ }_{\text {EtOH }} 255 \mathrm{~nm}$.

Substance (III) was neochlorogenic acid, $\mathrm{C}_{16} \mathrm{H}_{18} \mathrm{O}_{9}$. UV spectrum: $\lambda_{\max }$ EtOH $325,299,245 \mathrm{~nm}$.

Substance (IV) was chlorogenic acid, $\mathrm{C}_{16} \mathrm{H}_{18} \mathrm{O}_{9}$, mp 203-205 ${ }^{\circ} \mathrm{C}$. UV spectrum: $\lambda_{\max }{ }^{E t O H} 325,298,240 \mathrm{~nm}$. Alkaline hydrolysis led to the formation of equimolar amounts of caffeic and quinic acids. On heating with acetic anhydride, the pentaacetate was formed.

Substance (V) was ferulic acid, $\mathrm{C}_{10} \mathrm{H}_{10} \mathrm{O}_{4}, \mathrm{mp} 167-169^{\circ} \mathrm{C}$. UV spectrum: $\lambda_{\max }$ EtOH $330,320,236 \mathrm{~nm}$. The product of alkaline degradation was vanillic acid.

Substance (VI) was caffeic acid, $\mathrm{C}_{9} \mathrm{H}_{8} \mathrm{O}_{4}, \mathrm{mp} 197-200^{\circ} \mathrm{C}$. UV spectrum: $\lambda_{\max }$ EtOH $325,299,235 \mathrm{~nm}$. 3,4Dihydroxybenzoic acid was detected among the products of alkaline degradation.

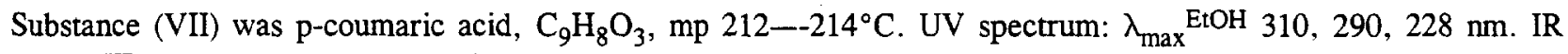
spectrum: $\lambda_{\max } \mathrm{KBr} 1310,1640,1705 \mathrm{~cm}^{-1}$. Alkaline degradation led to the formation of p-hydroxybenzoic cid.

Caffeic, chlorogenic, ferulic, p-hydroxybenzoic, and vanillic acids were detected in all the species investigated. pCoumaric acid was preent only in $A$. sieversiana, and neochlorogenic only in $A$. jacutical. The detection of caffeic and chlorogenic acids in $A$. sieversiana and $A$. absinthium agrees with the literature $[4,5]$. We are the first to have isolated phydroxybenzoic, vanillic, ferulic, p-coumaric, and neochlorogenic acids from the species investigated.

\section{REFERENCES}

1. E. N. Sal'nikova, N. F. Komissarenko, S. E. Dmytruk, and G. I. Kalinkina, Khim. Prir. Soedin., No.1, 136 (1992).

2. V. A. Bandyukova, Khim. Prir. Soedin., No. 3, 263 (1983).

3. J. R. Dyer, Applications of the Absorption Spectroscopy of Organic Compounds, Prentice-Hall, Englewood Cliffs, N.J. (1970).

4. I. I. Chemesova, L. M. Belenovskaya, and L. P. Markova, Khim. Prir. Soedin., No. 4, 521 (1982)

5. V. G. Minaeva, Medicinal Plants of Siberia [in Russian], Novosibirsk (1970).

Siberian State Medical Institute, Tomsk. State Scientific Center for Drugs, Khar'kov. Translated from Khimiya Prirodnykh Soedinenii, No. 5, pp. 759-760, September-October, 1993. Original article submitted May 4, 1993. 